\title{
中国东部木荷-米榰林的生物量和地上净初级 生产力
}

杨同辉 ${ }^{(1)}$ ，宋坤 ${ }^{(1)}$ ，达良俊 ${ }^{(1 *}$ ，李修鹏 ${ }^{(3)}$ ，吴健平 ${ }^{(1)}$

(1) 华东师范大学资源与环境科学学院, 上海 200062;

(2) 宁波市农业科学研究院，宁波 315040;

(3) 宁波市林特科技推广中心, 宁波 315012

* 联系人, E-mail: 1jda@des.ecnu.edu.cn

收稿日期: 2010-04-24; 接受日期: 2010-05-03

国家自然科学基金(批准号：30130060)、国家重点基础研究发展计划(批准号：G2000046801)和国家自然科学基金国际(地区)合作交流 (A3)项目资助

摘要运用样方重叠和树干解析法测定了浙江天童木荷-米槠群落生物量及生产力. 结果表 明, 群落总生物量为 $(225.3 \pm 30.1) \mathrm{t} / \mathrm{hm}^{2}$, 其中地上部分占 $72.0 \%$, 地下部分占 $28.0 \%, 87.2 \%$ 分 配于乔木层; 萌枝生物量较小, 其中 $95.0 \%$ 以上分布于灌木层. 群落地上部分生产力为 $(386.8 \pm 98.9) \mathrm{g} \cdot \mathrm{m}^{-2} \cdot \mathrm{a}^{-1}$, 其中 $96.0 \%$ 以上分配于乔木层, 树千对生产力的贡献最大, 叶的贡献率 最小. 中国亚热带常绿阔叶林群落生物量与林龄差异较大, 本研究的 52 年生木荷-米槠群落生 物量低于中国亚热带常绿阔叶林生物量的平均水平, 也较低于世界其他常绿阔叶林生物量水 平, 而且其生产力低于模型估算结果, 表明该群落在没有干扰的影响下, 群落生物量和生产 力发展潜力较大.

关键词

常绿阔叶林 群落生物量 净初级生产力 分配格局 木荷-米槠群落
森林生物量和生产力是森林生态系统结构和功 能的基础. 对于森林生态系统生物量和生产力的大 规模研究, 是从 20 世纪 60 年代中期国际生物学计划 (IBP) 中关于不同类型森林生物量和生产力的调查和 研究开始的 ${ }^{[1 \sim 11]} ; 20$ 世纪 80 年代后期, 随着对全球碳 循环研究的重视, 研究人员利用以前的样地生物量 和面积统计资料, 估算由于土地利用变化引起的区 域向大气中释放的碳量 ${ }^{[12 \sim 15]} .20$ 世纪 90 年代后期, 为了科学地评价森林生态系统在全球大气中碳源和 碳汇的作用, 开始研究森林生态系统的潜在生物量 和人类、自然干扰引起森林生态系统生物量和生产力
的动态变化过程 ${ }^{[16 ~ 20]} .21$ 世纪以来, 随着人们对森林 生态系统在全球变化中的作用的重视, 开始了生态 系统净生产量(NEP)的估算 ${ }^{[21 ~ 24]}$, 这不但包括森林中 植物物质的生物量和生产力，而且包括了土壤中的 有机物量和有机物积累量; 同时随着全球气候变化 对森林生态系统影响研究的不断深入, 对区域及全 球生产力的估算也成为一个研究热点 ${ }^{[25 ~ 30]}$.

亚热带常绿阔叶林是亚热带大陆东岸季风气候 区的典型植被类型 ${ }^{[31]}$, 在中国的分布较为广泛，东部 是常绿阔叶林分布的主要地区. 浙江天童的常绿阔 叶林是浙江东部丘陵地区地带性植被类型的一块难

英文版见: Yang T H, Song K, Da L J, et al. The biomass and aboveground net primary productivity of Schima superba-Castanopsis carlesii forests in east China. Sci China Life Sci, 2010, 53: 811-821, doi: 10.1007/s11427-010-4021-5 
得的代表性地段 ${ }^{[32]}$, 也是中国东部植被的典型类型 之一, 其生物量和生产力的测定对于阐明该地区森 林系统碳储量具有重要的基础意义. 运用样方重叠 和树干解析法测定了以木荷 (Schima superba)、米槠 (Castanopsis carlesii)为优势种的群落生物量和地上 生产力. 同时, 将该地区群落生物量与中国东部常绿 阔叶林其他群落生物量进行比较, 以阐明该地区常 绿阔叶林生产力水平及其发展潜力.

\section{1 研究区概况}

天童国家森林公园位于浙江省宁波市鄞州区 东南部, 距宁波市 $28 \mathrm{~km}, 29^{\circ} 48^{\prime} \mathrm{N}, 121^{\circ} 47^{\prime} \mathrm{E}$, 面积 $349 \mathrm{hm}^{2}$. 该地森林植被保存良好, 是浙江省东部丘 陵地区地带性植被类型的代表性地段. 气候为温暖潮 湿的亚热带季风气候. 年平均气温为 $16.2^{\circ} \mathrm{C}$, 最热月 为 7 月, 平均温度为 $28.1^{\circ} \mathrm{C}$; 最冷月为 1 月, 平均气温 为 $4.2^{\circ} \mathrm{C}$; 大于 $10^{\circ} \mathrm{C}$ 的年积温为 $5166.2^{\circ} \mathrm{C}, \mathrm{Kira}^{[33]}$ 的温 暖指数是 $135^{\circ} \mathrm{C}$. 月, 寒冷指数是 $-0.8^{\circ} \mathrm{C}$. 月. 年降水量 为 $1374.7 \mathrm{~mm}$, 多集中在夏季. 年平均相对湿度为 $82 \%$, 变率不大. 年蒸发量为 $1320.1 \mathrm{~mm}$, 小于降水 量. 森林公园内土壤主要为山地黄红壤, 成土母质主 要是中生代的沉积岩及部分酸性火成岩和花岗岩残 积风化物 ${ }^{[32]}$.

\section{2 研究方法}

\section{1 样地概况}

于天童放羊山东南坡 $\left(\mathrm{SE} 25^{\circ}\right.$ )海拔高度 $260 \mathrm{~m}$ 处 设置了 5 个 $20 \mathrm{~m} \times 20 \mathrm{~m}$ 的独立样方, 样地坡度 $25^{\circ} \sim$ $30^{\circ}$, 对其中 4 个样地进行了砍伐处理 ${ }^{[34]}$, 选择其中 3 个样方对其生物量进行了测定. 群落可分为 3 层, 乔 木层 $(H>8 \mathrm{~m})$ 、灌木层 $(1.5 \mathrm{~m}<H<8 \mathrm{~m})$ 、草本层 $(H<$ $1.5 \mathrm{~m})$. 群落优势种为木荷、米槠, 伴有石栎 (Lithocarpus glaber)、栲树 (C. fargesii)、细叶青冈 (Cyclobalanopsis myrsinaefolia), 林下灌木主要为山茶 科、山矾科、樟科植物, 草本层主要由偋类植物构成, 如狗脊(Woodwardia japonica)、红盖鳞毛䕬(Dryopteris erythrosora)、里白(Hicriopteris glauca) 等为主.

\section{2 生物量测定}

生物量测定采用样格重叠法(图 1), 由下至上分
层次先后测定, 并分开测定实生和萌生个体生物量. 实验处理于 2003 年 10 11 月完成.

(1) 枯枝落叶层和草本层生物量测定. 在各样 方内随机选取 1 个 $5 \mathrm{~m} \times 5 \mathrm{~m}$ 样格(图 1), 收集样格内 的枯枝落叶并分别称量; 木本植物分别收集茎和叶 速测鲜重; 草本和藤本全株称重.

（2）灌木层生物量测定. 在各样方的 $10 \mathrm{~m} \times$ $10 \mathrm{~m}$ 样格(图 1)内, 分种测定叶、枝、干鲜重.

（3）乔木层生物量测定. 采用标准木法, 即通 过建立标准木胸径 $(\mathrm{DBH})$ 与各器官生物量的关系(附 表 1), 推算乔木层生物量. 在各样方的乔木层和灌木 层中按径阶选择主要树种标准木 41 株(附表 1), 伐倒 后分种测定每株标准木叶、枝、干鲜重; 其他树种则 全部分器官进行鲜重测定.

(4) 根系生物量测定. 通过标准木胸径(DBH) 与根系生物量的关系(附表 2), 推算乔、灌木树种根 系生物量. 由于采伐样方需要进行恢复实验, 因此在 其边缘的同类型群落内, 按径阶选择了 8 株主要乔木 和灌木树种(附表 2), 全部挖取每株根系并称重; 同 时, 随机选择 3 个 $2 \mathrm{~m} \times 2 \mathrm{~m}$ 样格, 挖取所有草本层植 物根系称重.

所有鲜重样品均取其总质量的 5\%(总质量不足 $500 \mathrm{~g}$ 则全取)左右, 带回实验室, 于 $80^{\circ} \mathrm{C}$ 恒温干燥箱 中烘干至衡重后速测干重.

\section{3 年轮测定}

所有乔木树种个体于基部截取年轮盘, 打磨光 滑后, 用 WinDENDROTM2003a 年轮分析仪测定年 龄和年轮宽度 ${ }^{[35]}$, 其中乔木个体取 4 个方向判读, 灌 木个体取 2 个方向判读, 各方向年轮宽度的平均值为 当年年轮宽度，精度达 $0.001 \mathrm{~mm}$.

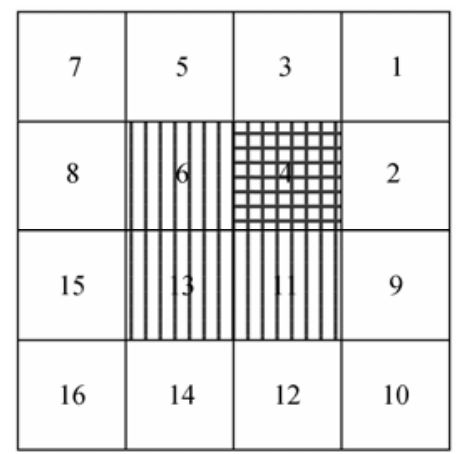

图 1 样方设置

每个样方由按顺序编号的 16 个 $5 \mathrm{~m} \times 5 \mathrm{~m}$ 的样格组成 


\section{4 地上净初级生产力测定}

（1）乔木层生产力测定. 由于林木基径与各器 官生物量之间存在明显的相关性 ${ }^{[31]}$, 从而通过建立 两者之间的相关关系(附表 1), 根据基径年轮宽度推算 林木个体近 5 年生物量增量, 可以估算其年生产力.

(2) 灌木层生产力测定. 灌木层中光照是决定 生产力的主要因子, 处于同一垂直空间水平上的树 种生产力相近. 因而, 将灌木层分 4 个高度级 $(1.5 \mathrm{~m}$ $<H \leqslant 2.0 \mathrm{~m}, 2.1 \mathrm{~m}<H \leqslant 4.0 \mathrm{~m}, 4.1 \mathrm{~m}<H \leqslant 6.0 \mathrm{~m}$, $6.1 \mathrm{~m}<H \leqslant 8.0 \mathrm{~m}$ )进行生产力估算. 灌木层树种由乔 木层树种幼树(包括 $1.5 \mathrm{~m} \leqslant \mathrm{H}$ 萌枝)和灌木树种组成, 乔木幼树生物量增量测定和乔木层树种测定方法相 同, 即根据乔木幼树标准木基径和器官生物量的相 关关系推算; 对于灌木树种个体, 则在每个高度级内 根据乔木幼树平均器官生物量增量平均值推算其近 5 年平均生产力, 从而推算出灌木层近 5 年平均生产力.

\section{3 结果与分析}

\section{1 群落生物量}

群落总生物量为 $(225.3 \pm 30.1) \mathrm{t} / \mathrm{hm}^{2}$ (表 1), 其中 地上部分生物量为 $(162.3 \pm 19.9) \mathrm{t} / \mathrm{hm}^{2}$, 占群落总生物 量的 $72.0 \%$, 其中活生物量为 $(157.4 \pm 17.7) \mathrm{t} / \mathrm{hm}^{2}$, 地 下部分生物量为 $(63.0 \pm 12.3) \mathrm{t} / \mathrm{hm}^{2}$, 占群落总生物量 的 $28.0 \%$, 群落地上、地下生物量分配比为 2.58 . 而 群落地上部分生物量 $90.8 \%$ 集中于乔木层, 达 (147.3 \pm 14.3$) \mathrm{t} / \mathrm{hm}^{2}$, 灌木层和调落物(枯立木、枯枝落 叶)层生物量较小, 分别占地上部分生物量的 $5.5 \%$ 和 $3.0 \%$, 草本层和藤本植物生物量占地上部分生物量 的比例均小于 $0.5 \%$.

从整个群落植物器官生物量来看, 器官生物量
大小顺序为干 $>$ 根 $>$ 枝 $>$ 叶. 其中乔木层植物的树干生 物量占层生物量的比例为 $50.0 \%$ 以上(表 2), 枝的生 物量 $(22.0 \%)$ 小于根的生物量 $(25.0 \%)$; 灌木层植物根 系的生物量最大 (43.2\%), 大于干的生物量 (39.2\%); 从乔木层到草本层植物干、枝的生物量分配比例逐渐 减少，而根系生物量分配比例在逐渐增加.

群落萌枝的总生物量为 $(2.1 \pm 1.5) \mathrm{t} / \mathrm{hm}^{2}$ (表 3$)$, 占 群落总生物量的 $0.3 \%$, 其中 $95.0 \%$ 以上分布于灌木 层, 而草本层中萌枝生物量仅占群落总生物量的 $0.1 \%$. 在灌木层中优势种米槠萌枝生物量最大, 占层 萌枝生物量的 $58.4 \%$; 其次是杨梅(Myrica rubra)、木 荷、细叶青冈及山矾 (Symplocos sumuntia), 其萌枝生 物量占层萌枝生物量的 $18.5 \%, 5.0 \%, 3.8 \%$ 和 $4.7 \%$, 其余各种萌枝生物量均小于 $1.0 \%$. 草本层中萌枝生 物量大部分由米槠构成, 其萌枝生物量占层萌枝生 物量的 $88.0 \%$, 其次是楉树, 为 $7.5 \%$.

\section{2 群落地上净初级生产力}

群落乔木层和灌木层地上部分生产力为 $(386.8 \pm$ 98.9) $\mathrm{g} \cdot \mathrm{m}^{-2} \cdot \mathrm{a}^{-1}$ (表 4), 其中 $96.0 \%$ 以上集中于乔木层, 达 $(373.0 \pm 104.8) \mathrm{g} \cdot \mathrm{m}^{-2} \cdot \mathrm{a}^{-1}$, 树干对生产力的贡献最大 (64.9\%), 叶的贡献率最低(6.6\%).

\section{表 1 群落各层生物量分配 (平均值 $\pm \mathrm{SD})^{\mathrm{a})}$}

\begin{tabular}{|c|c|c|c|}
\hline \multicolumn{2}{|c|}{ 层次 } & 生物量 $/ \mathrm{t} \cdot \mathrm{hm}^{-2}$ & 比例(\%) \\
\hline \multirow{6}{*}{ 地上部分 } & 乔木层 & $147.3 \pm 14.3$ & $65.4(90.8)$ \\
\hline & 灌木层 & $8.9 \pm 5.6$ & $4.0(5.5)$ \\
\hline & 草本层 & $0.7 \pm 0.2$ & $0.3(0.4)$ \\
\hline & 调落物 & $4.9 \pm 1.8$ & $2.2(3.0)$ \\
\hline & 藤本 & $0.5 \pm 0.7$ & $0.2(0.3)$ \\
\hline & 地上部合计 & $162.3 \pm 19.9$ & 72.0 \\
\hline 地下部分 & & $63.0 \pm 12.3$ & 28.0 \\
\hline 总计 & & $225.3 \pm 30.1$ & 100 \\
\hline
\end{tabular}

a) 括号内数字示群落地上各层生物量分配比例

\section{表 2 群落器官生物量分配 $(\text { 平均值 } \pm \mathrm{SD})^{\mathrm{a}}$}

\begin{tabular}{|c|c|c|c|c|c|}
\hline \multirow{2}{*}{ 层次 } & \multicolumn{3}{|c|}{ 地上部分 $/ \mathrm{t} \cdot \mathrm{hm}^{-2}$} & \multirow{2}{*}{$\begin{array}{c}\text { 地下部分 } / \mathrm{t} \cdot \mathrm{hm}^{-2} \\
\text { 根 }\end{array}$} & \multirow{2}{*}{ 总计 $/ \mathrm{t} \cdot \mathrm{hm}^{-2}$} \\
\hline & 叶 & 枝 & 干 & & \\
\hline 乔木层 & $5.0 \pm 1.2$ & $43.3 \pm 5.9$ & $98.9 \pm 20.5$ & $49.1 \pm 16.8$ & $196.4 \pm 18.2^{\mathrm{a}}$ \\
\hline 比例(\%) & 2.5 & 22.0 & 50.4 & 25.0 & \\
\hline 灌木层 & $0.9 \pm 0.6$ & $1.8 \pm 1.1$ & $6.1 \pm 3.9$ & $6.8 \pm 2.1^{\mathrm{b}}$ & $15.7 \pm 7.5$ \\
\hline 比例(\%) & 5.9 & 11.7 & 39.2 & 43.2 & \\
\hline 草本层 & $0.1 \pm 0.1$ & \multicolumn{2}{|c|}{$0.4 \pm 0.2$} & $7.2 \pm 5.9$ & $7.9 \pm 5.9^{c}$ \\
\hline 比例(\%) & 1.6 & \multicolumn{2}{|c|}{4.7} & 91.3 & \\
\hline
\end{tabular}

a) a: 包括果实生物量; b: 包括藤本植物根系生物量; c: 包括草本植物生物量 
表 3 群落地上各层萌枝生物量分配 $(\bar{x} \pm \mathbf{S D})$

\begin{tabular}{ccccc}
\hline \multirow{2}{*}{ 层次 } & \multicolumn{3}{c}{ 生物量 $/ \mathrm{t} \cdot \mathrm{hm}^{-2}$} & \multirow{2}{*}{ 总计 } \\
\cline { 2 - 4 } & 叶 & 枝 & 干 & \\
\hline 灌木层 & $0.1 \pm 0.1$ & $0.4 \pm 0.3$ & $1.5 \pm 1.1$ & $2.0 \pm 1.4$ \\
$(\%)$ & 6.9 & 20.0 & 73.13 & 100 \\
草本层 & $0.027 \pm 0.016$ & $0.068 \pm 0.048$ & $0.095 \pm 0.064$ \\
$(\%)$ & 28.2 & \multicolumn{2}{c}{71.8} & 100 \\
\hline
\end{tabular}

表 4 群落各层地上部分净初级生产力 $(\bar{x} \pm \mathrm{SD})^{\mathrm{a})}$

\begin{tabular}{ccccc}
\hline \multirow{2}{*}{ 层次 } & \multicolumn{3}{c}{ 净初级生产力 $/ \mathrm{g} \cdot \mathrm{m}^{-2} \cdot \mathrm{a}^{-1}$} & \multirow{2}{*}{ 总计 } \\
\cline { 2 - 4 } & 叶 & 枝 & 干 & \\
\hline 乔木层 & $24.5 \pm 15.0$ & $98.4 \pm 31.1$ & $242.1 \pm 63.5$ & $373.0 \pm 104.8^{\mathrm{a}}$ \\
$(\%)$ & 6.6 & 26.4 & 64.9 & $100^{\mathrm{b}}$ \\
灌木层 & $3.1 \pm 2.1$ & $2.5 \pm 2.0$ & $8.2 \pm 5.7$ & $13.8 \pm 9.8$ \\
$(\%)$ & 21.8 & 20.0 & 58.2 & 100 \\
\hline
\end{tabular}

a) a, b: 包括每年果实产量

\section{4 讨论}

\section{1 中国常绿阔叶林群落生物量}

根据常绿阔叶林分区 ${ }^{[36,37]}$, 统计了已经报道的 中国常绿阔叶天然林群落生物量的研究结果(表 5). 可见, 在所涉及的 19 个常绿阔叶林群落类型中, 东 部为 8 个, 西部为 11 个, 主要涉及栲类、青冈类、木 荷类、石栎类等群落类型. 其中活生物量最大的是鼎 湖山的格木(Erythrophleum fordii) 林, 为 $568.2 \mathrm{t} / \mathrm{hm}^{2}$; 最小的是 12 年生短刺楉 (Castanopsis echidnocarpa) 林, 仅 $87.8 \mathrm{t} / \mathrm{hm}^{2}$. 东部典型常绿阔叶林平均生物量 为 $251.6 \mathrm{t} / \mathrm{hm}^{2}$, 平均林龄在 40 年左右; 季节常绿阔 叶林和西部典型常绿阔叶林平均群落生物量分别为 331.7 和 $335.8 \mathrm{t} / \mathrm{hm}^{2}$, 多数为成熟林. 本研究的 52 年 生木荷-米槠林群落生物量虽然高于约 35 年青冈 (Cylobalanopsis glauca) 林、楉树林、木荷林及 42 年 短刺栲林等生物量, 但却明显低于约 35 年生的红栲 (Castanopsis hystrix)林和福建青冈 (Cylobalanopsis chungii)林生物量, 表明除林龄差异外, 群落优势种 类和生态习性、区域气候、立地条件等因素都是影响 群落生物量差异的重要因素.

\section{2 中国常绿阔叶林总生物量估算}

目前研究森林生态系统生物量和生产力的方法 主要有两种, 一种是利用现有实测资料进行推算, 另 一种是利用气候数据、遥感手段等结合广义生态模型 进行估算.
为了更好地从群落角度理解中国常绿阔叶林总 体生物量水平, 根据现有实测数据, 具体结合中国植 被图 ${ }^{[56]}$, 采用“平均生物量法”对中国常绿阔叶林生 物量进行估算. 即根据中国常绿阔叶林分区方案 ${ }^{[57]}$, 将中国常绿阔叶林群系(包括台湾岛)划分为不同的 “集群”(非分类单位，群系的集合，比群系组大), 每 个集群基本上均有实测样点数据, 根据每个集群实 测样点生物量平均值与集群植被分布面积, 便可核 算出每个集群总的生物量, 从而推算出整个常绿阔 叶林总生物量(表 6).

(1) 东部典型常绿阔叶林划分为 3 个集群: 青 冈一石栎集群、栲-木荷集群和樟-楠集群. 青冈一石栎 集群包括林木层的优势种是青冈属、石栎属的种类， 进行过生物量系统测定的有青冈林 ${ }^{[45]}$ 、青冈-硬叶樟 林 ${ }^{[50]}$ 、福建青冈林 ${ }^{[51]}$ 等; 楉-木荷集群林木层的优势 种是楉属、木荷属的种类, 进行过生物量系统测定 的有木荷林 ${ }^{[46]}$ 、甜槠 (Castanopsis eyrei) 林 ${ }^{[47]}$ 、木荷米槠林、楉树林 ${ }^{[48]}$ 、红栲-青冈-刨花楠(Machilus pauhoi) 林 ${ }^{[49]}$ 等; 樟-楠集群林木层的优势种是樟属、 润楠属和楠属及含笑属的种类, 目前只进行了楠木 (Phoebe bournei) 人工林 ${ }^{[58 \sim 60]}$ 的生物量测定.

(2) 西部典型常绿阔叶林划分为 2 个集群: 栲-青 冈集群和木荷-石栋集群. 前者组成乔木层的优势种为 楉类和滇青冈(Cylobalanopsis glaucoides)等, 标志种 为滇青冈、黄毛青冈(C. delavayii)、元江栲(Castanopsis arthacantha $)$ 、高山栲 $($ C. delavyii) 等, 已有生物量测定 数据的有元江栲林 ${ }^{[54]}$ 、黄毛青冈林 ${ }^{[55]}$; 后者乔木层的 优势种为石栎属、木莲属种类及滇木荷 (Schima noronhae)等, 已有木果石栋(Lithocarpus variolosus) 林 ${ }^{[52,53]}$ 等生物量测定数据.

（3）季节常绿阔叶林为 1 个集群，包括大陆东部 季节常绿阔叶林、大陆西部季节常绿阔叶林及台湾季 节常绿阔叶林, 进行过生物量系统测定的有鼎湖山 黄果厚壳桂(Cryptocarya concinna) 林 $^{[38,39]}$ 和厚壳桂 $($ C. chinensis) 林 ${ }^{[40]}$ 、黑石顶粘木(Ixonannthes chinensis) 林 $^{[42]}$ 和云南短刺栲林 ${ }^{[43]}$.

（4）秋茄-桉树-木麻黄集群，包括大陆东南部沿海 和西部的秋茄(Kandelia candel) 林、木麻黄(Casuarina equisetifolia) 林和桉树林, 其中木麻黄林和桉树林为 多人工林，计入常绿阔叶林分布面积, 目前进行过生 物量系统测定的天然林仅有秋茄林 ${ }^{[61]}$, 木麻黄 ${ }^{[62]}$ 和 桉树 ${ }^{[63]}$ 人工林生物量测定较多. 
按照上述集群划分，估算中国常绿阔叶林总生 物量为 $4.05 \operatorname{Pg}$ (表 6 , 假定含碳量 $50 \%$, 换算为 2.02 $\mathrm{Pg} C)$, 该结果仅为赵敏 ${ }^{[64]}$ 利用 CENTURY 模型模拟 的常绿阔叶林生物总产量 $(4.50 \mathrm{PgC})$ 的 $1 / 2$, 罗天祥 ${ }^{[65]}$ $(2.54 \mathrm{Pg} \mathrm{C})$ 、方精云 ${ }^{[66]}(1.39 \mathrm{Pg} \mathrm{C}) 、$ 周玉荣等人 ${ }^{[67]}$
$(1.33 \mathrm{Pg} \mathrm{C}$ )利用全国森林调查数据估算结果的 $0.8 \sim 1.6$ 倍, 是王效科等人 ${ }^{[68}$ 利用 1994 年以前生物量 样地报道数据估算结果 $(0.20 \mathrm{Pg} \mathrm{C})$ 的 10 倍多. 从目 前研究来看，由于方法差异而致所得结果不同；而且 现有群落调查数据时间跨度较大，常绿阔叶林生物量

表 5 中国常绿阔叶林生物量及分配

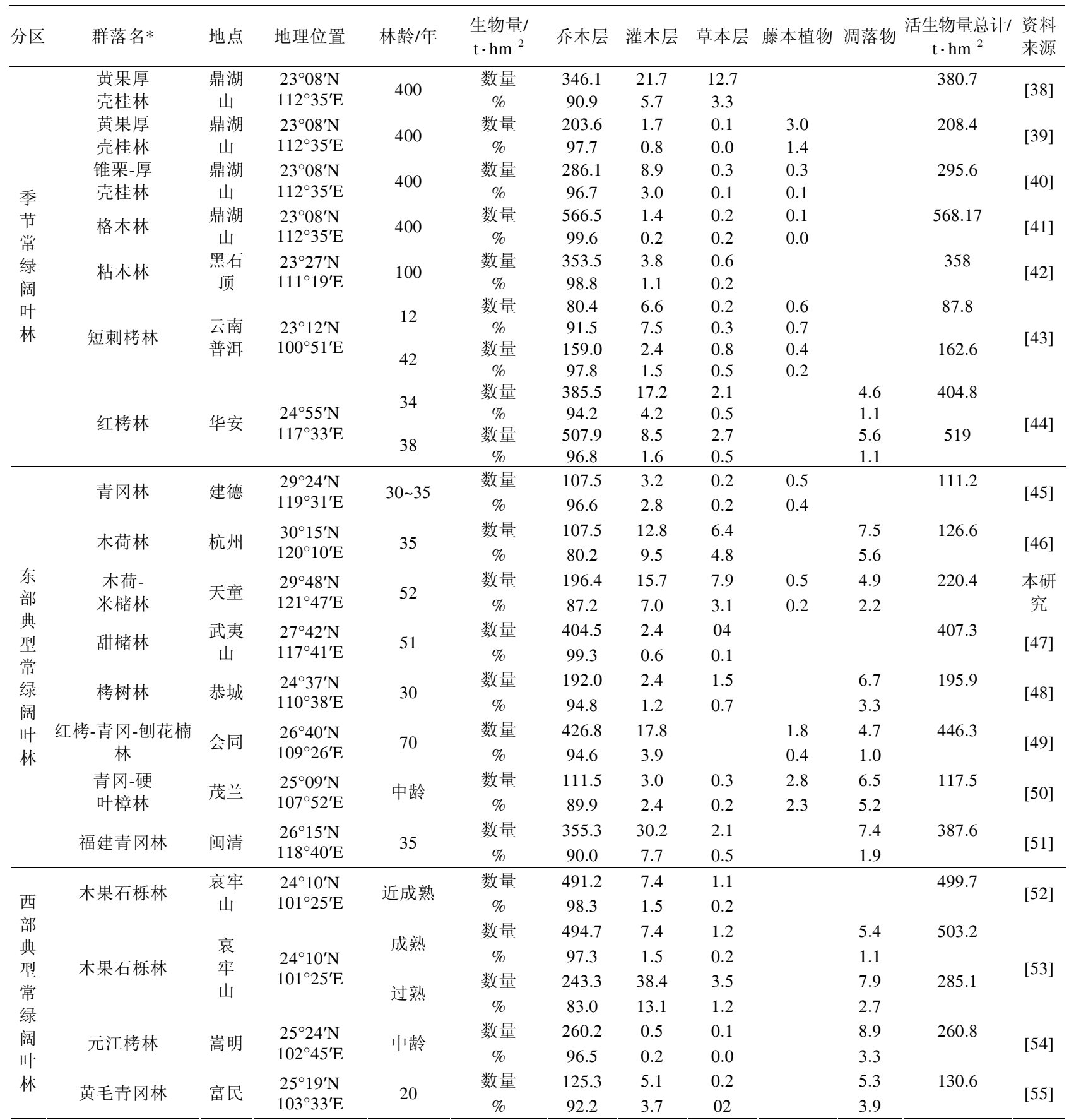


表 6 中国常绿阔叶林分区及其生物量估算

\begin{tabular}{|c|c|c|c|c|}
\hline \multicolumn{2}{|c|}{ 集群分布 } & 面积 $/ \times 10^{6} \mathrm{hm}$ & 平均群落生物量 $/ \mathrm{t} \cdot \mathrm{hm}^{-2}$ & 总生物量 $/ \mathrm{Pg}$ \\
\hline \multirow{3}{*}{ 东部 } & 栲-木荷 & 27.7 & 336.3 & 0.93 \\
\hline & 青冈-石栋 & 33.7 & 210.1 & 0.71 \\
\hline & 樟-楠 & 0.5 & 179.9 & 0.01 \\
\hline \multirow{2}{*}{ 西部 } & 木荷-石栋 & 11.8 & 433.8 & 0.51 \\
\hline & 栲-青冈 & 18.7 & 202.8 & 0.38 \\
\hline \multicolumn{2}{|c|}{ 季节常绿阔叶林 } & 50.6 & 294.5 & 1.49 \\
\hline \multicolumn{2}{|c|}{ 秋茄-木麻黄-桉树 } & 1.1 & 125.6 & 0.01 \\
\hline \multicolumn{2}{|c|}{ 总计 } & & & 4.05 \\
\hline
\end{tabular}

估算方面仍存在不确定性, 从而为数据的可比性带 来困难. 此外, 以往研究很少考虑类型间的差异, 多 以平均生物量法进行总生物量估算, 导致结果出现 差异. 总的来说, 常绿阔叶林类型多样, 加之立地条 件异质性高, 导致不同群落类型生物量差异较大. 因 而增加常绿阔叶林生物量估算的精度, 需要弄清每 一类型常绿阔叶林的生物量, 而目前所展开的研究 十分有限.

\section{3 全球常绿阔叶林群落生物量}

常绿阔叶林主要分布于东亚的中国、日本、朝鲜 半岛, 北美的佛罗里达半岛和加利福尼亚, 南美的智 利, 非洲的那利群岛, 大洋洲的澳大利亚、新西兰及 北大西洋的马德拉群岛和加纳利群岛等地 ${ }^{[69]}$. 近几 十年来, 日本、美国、新西兰、澳大利亚、智利等都 对常绿阔叶林开展了生物量研究, 表 7 汇集了全球典 型常绿阔叶群落的生物量测定结果, 其中部分群落 只测定了地上部分生物量. 在测定方法上, 中国与世 界其他地区略有不同, 中国常绿阔叶林群落生物量
测定多采用直接收获法(灌木层草本层)和相对生长 法(乔木层), 而国外多采用相对生长法(所有林木树 种), 其中新西兰假山毛榉林(Nothofagus truncata) 在 测定群落生物量时采用了统一的林木树种各器官生 物量与 $\mathrm{DBH}$ 的回归模型. 就地上部分生物量而言, 达到成熟林阶段的新西兰假山毛榉林生物量最大

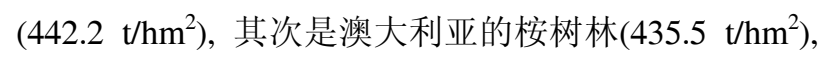
而本研究的木荷-米楮林生物量最小. 以整个群落生 物量而言, 位于新西兰新南威尔士的假山毛榉林生 物量最大, 达到了 $585.4 \mathrm{t} / \mathrm{hm}^{2}$; 其次是日本水俣长尾 栲林(Castanopsis cuspidata), 为 $378.6 \mathrm{t} / \mathrm{hm}^{2}$; 美国南 卡罗莱纳州的月桂叶栎(Quercus laurifolia) 林生物量 最小 $\left(217.6 \mathrm{t} / \mathrm{hm}^{2}\right)$. 总的来看, 相对成熟的林分都具 有较高的生物量, 而且较为接近, 中国区域成熟林生 物量在 295.0 568.0 t/ $\mathrm{hm}^{2}$ 之间, 国外的在 242.0 585.0 $\mathrm{t} / \mathrm{hm}^{2}$ 之间.

\section{4 群落生产力}

由于缺少对中国东部常绿阔叶林生产力的实测

表 7 全球常绿阔叶林生物量及分配

\begin{tabular}{|c|c|c|c|c|c|c|c|}
\hline \multirow{2}{*}{ 群落名 } & \multirow{2}{*}{ 地点 } & \multirow{2}{*}{ 地理位置 } & \multirow{2}{*}{ 林龄/年 } & \multicolumn{3}{|c|}{ 生物量 $/ \mathrm{t} \cdot \mathrm{hm}^{-2}$} & \multirow{2}{*}{ 资料来源 } \\
\hline & & & & 地上部分 & 地下部分 & 总计 & \\
\hline 木荷-米䅣林 & 中国天童 & $\begin{array}{r}29^{\circ} 48^{\prime} \mathrm{N} \\
121^{\circ} 47^{\prime} \mathrm{E}\end{array}$ & 52 & 162.3 & 63.0 & 225.3 & 本研究 \\
\hline 月桂叶栎林 & $\begin{array}{l}\text { 美国南卡 } \\
\text { 罗莱纳州 }\end{array}$ & $\begin{array}{l}33^{\circ} \mathrm{N} \\
82^{\circ} \mathrm{W}\end{array}$ & 60 & 207.0 & 10.6 & 217.6 & [70] \\
\hline 长尾栲林 & 日本水俣 & $\begin{array}{c}32^{\circ} 10^{\prime} \mathrm{N} \\
130^{\circ} 28^{\prime} \mathrm{E}\end{array}$ & 65 & 330.3 & 48.3 & 378.6 & {$[71]$} \\
\hline 假山毛榉林 & $\begin{array}{l}\text { 新西兰 } \\
\text { 尼尔森 }\end{array}$ & $\begin{array}{c}41^{\circ} 31^{\prime} \mathrm{S} \\
172^{\circ} 45^{\prime} \mathrm{E}\end{array}$ & 成熟林 & 442.2 & 143.2 & 585.4 & [72] \\
\hline 月桂林 & 加纳利岛 & $\begin{array}{l}28^{\circ} 19^{\prime} \mathrm{N} \\
16^{\circ} 34^{\prime} \mathrm{W}\end{array}$ & 成熟林 & 242.5 & & & [73] \\
\hline 假山毛榉林 & 智利岛 & $\begin{array}{c}42^{\circ} 30^{\prime} \mathrm{S} \\
74^{\circ} \mathrm{W}\end{array}$ & 成熟林 & 381.0 & & & [74] \\
\hline 桉树林 & $\begin{array}{l}\text { 澳大利亚 } \\
\text { 新南威尔士 }\end{array}$ & $\begin{array}{c}37^{\circ} \mathrm{S} \\
149^{\circ} 30^{\prime} \mathrm{E}\end{array}$ & 成熟林 & 435.5 & & & [75] \\
\hline
\end{tabular}


研究, 该地区的生产力以往多为模型估算值. 本研究 中群落地上净第一生产力为 $386.8 \mathrm{~g} \cdot \mathrm{m}^{-2} \cdot \mathrm{a}^{-1}$, 而国内已 有研究表明, 常绿阔叶林群落地下净第一生产力约占 群落总净第一生产力的 $8.6 \%$ 24.3\% ${ }^{[39,42,43,45 \sim 47,54,55]}$. 据 此估算, 本研究群落总净第一生产力为 423.2 511.0 $\mathrm{g} \cdot \mathrm{m}^{-2} \cdot \mathrm{a}^{-1}$ (假定含碳量 $50 \%$, 换算为 $211.6 \sim 255.5$ $\mathrm{gC} \cdot \mathrm{m}^{-2} \cdot \mathrm{a}^{-1}$ ), 最接近于倪健 ${ }^{[76]}$ 利用筑后(Chikugo)模型 估算的中国亚热带常绿阔叶林北部亚地带的 NPP 最 小值 $\left(590.0 \mathrm{~g} \cdot \mathrm{m}^{-2} \cdot \mathrm{a}^{-1}\right.$, 假定含碳量 $50 \%$, 换算为 295 $\left.\mathrm{gC} \cdot \mathrm{m}^{-2} \cdot \mathrm{a}^{-1}\right)$, 而与柯金虎等人 ${ }^{[77]}$ 利用 CASA 模型估算 的中国长江流域常绿阔叶林年 NPP 的平均值(365.0 $\left.\mathrm{gC} \cdot \mathrm{m}^{-2} \cdot \mathrm{a}^{-1}\right)$ 及与朴世龙等人 ${ }^{[78]}$ 利用 CASA 模型估算的 常绿阔叶林年 NPP 平均值 $\left(525.0 \mathrm{gC} \cdot \mathrm{m}^{-2} \cdot \mathrm{a}^{-1}\right)$ 差距较
大. 周广胜等人 ${ }^{[79]}$ 基于综合模型估算的亚热带常绿 阔叶林北部亚地带的 NPP 最小值是此群落 NPP 的 4 倍多.

总体上，估算的亚热带常绿阔叶林的年 NPP 均 高于本研究的 NPP 水平. 本研究中的木荷-米槠群落 处于东部常绿润叶林的中北部亚地带, 而且优势种 米槠已达到其分布北界, 其 NPP 可能低于整个东部 常绿阔叶林的 NPP 平均值. 此外, 多数 NPP 估算模 型主要基于光、热和水等环境因素进行推算, 其估算 的 NPP 是区域潜在的 NPP 或是理想状态下植被所能 达到的最大 NPP, 而现实群落可能受到人为或自然 干扰的影响, 尤其本研究地区人类活动频繁, 季节性 台风影响比较明显, 难以达到最大值.

\section{参考文献}

1 Ogawa H, Yoda K, Ogino K, et al. Comparative ecological studies on three main types of forest vegetation in Thailand: II. Plant biomass. Nat Life Southeast Asia (Kyoto), 1965, 1: 49-80

2 Ovinghton J D, Heitkamp D, Lawrence D B. Plant biomass and productivity of prairie, savanna, oak woods and maize field ecosystems in central Minnesota. Ecology, 1963, 44: 52-63

3 Whittaker R H. Forest dimension and production in the Great Smoky Mountains. Ecology, 1966, 47: 103-121

4 Duvingneaud P. Productivity of forest ecosystems, Proc. Brussels Symp. UNESCO. Ecol Conserv, 1969, 4: 1—684

5 Satoo T. A synthesis of studies be the harvest method: primary production relations in ht temperate deciduous forest of Japan. In: analysis of temperate forest ecosystem. Ecology Study. New York: Springer-Verlag, 1970. 1: 55-72

6 Anderson F. Ecological studies in a Scandinavian woodland and meadow area, Southern Sweden. 2. Plant biomass, primary production and turnover of organic matter. Botany Notiser, 1970, 123: 8-51

7 Leith H, Whittaker(eds.)R H. Primary productivity of biosphere.Berlin: Springer-Verlag, 1975

8 Maclean D A, Wein R W. Biomass of jack pine and mixed hardwood stands in southern New Brunswich. Can J of Forest Res, 1976, 6: $441-447$

9 Jordan C F. Amazon rain forest. Am Sci, 1982, 70: 394-401

10 Cannell M G R. World forest biomass and primary production data. London: Academic Press, 1982

11 Olson J S, Watts J K, Allison L J. Major world ecosystems ranked by carbon in live vegetation: a database. NDP-017, TN, Oak Ridge National Laboratory, 1985

12 Houghton R A, Hobbie J E, Mellilo J M, et al. Changes in the carbon content of terrestrial biota and soils between 1860 and 1980: a net release of $\mathrm{CO}_{2}$ to the atmosphere. Ecol Monogr, 1983, 53: 235-262

13 Houghton R A, Boone R D, Mellilo J M, et al. Net flux of carbon dioxide from tropic forests in 1980. Nature, 1985, 316: 617-620

14 Houghton R A, Boone R D, Fruci J R, et al. The flux of carbon from terrestrial ecosystems to the atmosphere in 1980, due to changes in land use: geographic distribution of the globe flux. Tellus, 1985, 39B: 122-139

15 Grubler A. Enhancing carbon sink. Energy, 1993, 18: 499-522

16 Iverson L R, Brown S, Grainger A, et al. Carbon sequestration in tropic Asia: an assessment of technically suitable forest land using geographical information systems analysis. Clim Res, 1993, 3: 23-38

17 Iverson L R , Brown S, Prasad A, et al. Use of GIS for estimating potential and actural forest biomass for continental south and southeast 
Asia, In: effect of land use change on atmospheric $\mathrm{CO}_{2}$ concentrations: south and southeast Asia as a case study. Dale V H, ed. New York: Springer-Verlag, 1994. 67-116

18 Dixon R K, Brown S, Houghton R A, et al. Carbon pool and flux of global forest ecosystem. Science, 1994, 263: 185-190

19 Houghton R A. Temporal patterns of land-use change and carbon storage in China and tropical Asia. Sci China C: Life Sci, 2002, 45: $10-17$

20 Rodel D L. Forest carbon budgets in Southeast Asia following harvesting and land cover change. Sci China C: Life Sci, 2002, 45: 55-64

21 Fang J Y, Chen A P, Peng C H, et al. Changes in forest biomass carbon storage in China between 1949 and 1998. Science, 2001, 292: $2320-2322$

22 Clark D A, Brown S, Kicklighter D W, et al. Net primary production in tropical forests: an evaluation and synthesis of existing field data. Ecol Appl, 2001, 11:371-384

23 Ni J. Net primary productivity in forests of China: scaling-up of national inventory data and comparison with model predictions. Forest Ecol Manage, 2003, 176: 485-495

24 Zhao M, Zhou G S. Estimation of biomass and net primary productivity of major planted forests in China based on forest inventory data. Forest Ecol Manage, 2005, 207: 295-313

25 Potter C S, Randerson J T, Field C B, et al. Terrestrial ecosystem production: a process model base on global satellite and surface data. Global Biogeochem Cy, 1993, 7: 811-841

26 Ruimy A, Saugier B. Methodology foe the estimation of terrestrial net primary production from remotely sensed data. Journal of Geoph Res, 1994, 99: 5263-5283

27 Ichii K, Matsui Y, Yamaguchi Y, et al. Comparison of global net primary production trends obtained from satellite-based normalized difference vegetation index and carbon cycle model. Global Biogeochem Cy, 2001, 15: 351-363

28 朴世龙, 方精云, 郭庆华. 1982-1999 年中国植被净第一性生产力及其时空变化.北京大学学报(自然科学版), 2001, 37: 563一 -569

29 朱文泉, 潘耀忠, 张锦水. 中国陆地植被净初级生产力遥感估算. 植物生态学报, 2007, 31: 413-424

30 郭浩, 王兵, 马向前, 等. 中国油松林生态服务功能评估. 中国科学 C 辑: 生命科学, 2008, 38: 565一 572

31 冯宗伟, 王效科, 吴刚. 中国森林生态系统的生物量和生产力. 北京: 科学出版社, 1999

32 宋永昌, 王祥荣. 浙江天童国家森林公园的植被和区系. 上海: 上海科学技术文献出版社, 1995

33 Kira T. A new classification of climate in Eastern Asian as the basis for agricultural geography. Kyoto: Horticultural Institute, 1945

34 达良俊, 宋坤. 浙江天童受损常绿阔叶林实验生态学研究( I ): 生态恢复实验与长期定位. 华东师范大学学报(自然科学版), 2008, 4: $1-11$

35 宋坤, 杨徐峰, 康敏明, 等. 浙江天童受损常绿阔叶林实验生态学研究( II): 主要常绿树种的生长格局. 华东师范大学学报(自然科 学版), 2008, 4: 12-24

36 宋永昌. 中国东部森林植被带划分之我见. 植物学报, 1999, 41: 541一-552

37 Fang J Y, Song Y C, Liu H Y, et al. Vegetation-climate relationship and its application in division of vegetation zone in China. Acta Bot Sinica, 2002, 44: 1105-1122

38 彭少麟, 张祝平. 鼎湖山地带性植被生物量、生产力和光能利用效率. 中国科学 B 辑, 1994, 24: 497-502

39 张祝平, 丁明禁. 鼎湖山亚热带季风常绿阔叶林的生物量和光能利用效率. 生态学报, 1996, 15: 525-534

40 温达志, 魏平, 孔国辉, 等. 鼎湖山雉栗+黄果厚壳桂+荷木群落生物量及其特征. 生态学报, 1997, 17: 497一504

41 蚁伟民, 张祝平, 丁明惁, 等. 鼎湖山格木群落的生物量和光能利用效率. 生态学报, 2000, 20: 397-403

42 陈章和, 王伯䔉, 张宏达. 亚热带常绿阔叶林的生产力. 广州: 广东高等教育出版社, 1996

43 党承林, 吴兆录. 季风常绿阔叶林短刺栲群落的生物量研究. 云南大学学报(自然科学版), 1992, 14: 95-107

44 黄全能. 红锥天然林生长规律与生物量的调查研究. 福建林业科技, 1998, 25: 20-23

45 陈启瑺. 青冈林生产力研究. 杭州: 杭州大学出版社, 1993

46 余益武, 施德法, 蒋秋怡, 等. 杭州木荷次生林生物量的研究. 浙江林学院学报, 1993, 10: 157-161

47 林益明, 林鹏, 李振基, 等. 武夷山甜槠群落的生物量和生产力. 厦门大学学报(自然科学版), 1996, 35: 269-275

48 卢琦. 栲树林生物生产力模型. 广西农学院学报, 1990, 9: 55-64

49 邓仕坚, 廖利平, 汪思龙, 等. 湖南会同红栲-青冈-刨花楠群落生物生产力的研究. 应用生态学报, 2000, 11: 651一 654

50 杨汉奎, 程仕泽. 贵州茂兰喀斯特森林群落生物量研究. 生态学报, 1991, 11: 307-312

51 黄典忠. 闽江下游福建青冈次生林群落的生物量特征. 防护林科技, 2006, 70: 16-18

52 邱学忠, 谢寿昌, 荆桂芳. 云南哀牢山徐家坝地区木果石栋林生物量的初步研究. 云南植物研究, 1984, 6: 85-92

53 谢寿昌, 刘文耀, 李寿昌, 等. 云南哀牢山中山湿性常绿阔叶林生物量的初步研究. 植物生态学报, 1996, 20: 167一176 
54 党承林, 吴兆录. 元江栲群落的生物量研究. 云南大学学报(自然科学版), 1994, 16: 195-199

55 党承林, 吴兆录. 黄毛青冈群落的生物量研究. 云南大学学报(自然科学版), 1994, 16: 205-209

56 中国科学院中国植被图编辑委员会. 1: 1000000 中国植被图集. 北京：科学出版社, 2001

57 宋永昌. 中国常绿榈叶林分类试行方案. 植物生态学报, 2004, 28: 435-448

58 廖涵宗, 张春能, 陈德叶. 人工楠木林的生物量. 福建林学院学报, 1988, 8: 252-257

59 彭龙福. 35 年生楠木人工林生物量及生产力的研究. 福建林学院学报, 2003, 23: 128-131

60 马明东, 江洪, 刘跃建. 楠木人工林生态系统生物量、碳含量、碳咜量及其分布. 林业科学, 2008, 44: 34-39

61 林鹏, 卢昌义, 林光辉, 等. 九龙江口红树林研究 I. 秋茄群落的生物量和生产力. 厦门大学学报(自然科学版), 1985, 24: 508一 514

62 叶功富, 吴锡麟, 张清海, 等. 沿海防护林生态系统不同群落生物量和能量的研究. 林业科学, 2003, 31: 8-14

63 张琼, 洪伟, 吴承祯, 等. 不同桉树人工林生物量与生产力的比较分析. 福建林学院学报, 2006, 26: 218一223

64 赵敏. 中国主要森林生态系统碳储量和碳收支评估. 北京: 中国科学院植物研究所, 2004

65 罗天祥. 中国主要森林类型生物生产力格局及其数学模型. 北京: 中国科学院国家计划委员会-自然资源考察委员会, 1996

66 方精云. 中国森林生产力及其对全球气候变化的响应. 植物生态学报, 2000, 24: 513-517

67 周玉荣, 于振良, 赵士洞. 中国主要森林生态系统碳捾量和碳平衡. 植物生态学报, 2000, 24: 518一 522

68 王效科, 冯宗炜, 欧阳志云. 中国森林生态系统的植物碳储量和碳密度研究. 应用生态学报, 2001, 12: 13-16

69 宋永昌, 陈小勇, 王希华. 中国常绿阔叶林研究的回顾与展望. 华东师范大学学报(自然科学版), 2005, 1: 1-8

70 Laura A B G, Aust W M, Randall K K, et al. Biomass and carbon pools of disturbed riparian forests. Forest Ecol Manage, 2003, 180: $493-508$

71 Kira T, Ono Y, Hosokawa T. Biological production in a warm-temperate evergreen oak forest of Japan-JIBP synthesis volume 18. Tokyo: University of Tokyo Press, 1978

72 Hart B P S, Clinton P W, Allen, et al. Biomass and macro-nutrients(above-and below-ground)in a New Zealand beech(Nothofagus)forest ecosystem: implications for carbon storage and sustainable forest management. Forest Ecol Manage, 2003, 174: 281—294

73 Jesús R A, José R A, Angel F. Allometric relationships of different tree species and stand above ground biomass in the Gomera laurel forest(Canary Island). Flora, 2005, 200: 264-274

74 Martin R C, Juan J A, Juan C A, et al. Coarse woody debris biomass in successional and primary temperate forests in Chiloé Island, Chile. Forest Ecol Manage, 2002, 164: 265-275

75 John T, Marcia J L. Effects of forest harvesting nutrient removals on soil nutrient reserves. Oecologia, 1986, 70: 140—148

76 倪健. 中国亚热带常绿阔叶林净第一性生产力的估算. 生态学杂志, 1996, 15: 1-8

77 柯金虎, 朴世龙, 方精云. 长江流域植被净第一生产力及其时空格局研究. 植物生态学报, 2003, 27: 764一770

78 朴世龙, 方精云, 郭庆华. 利用 CASA 模型估算中国植被净第一生产力. 植物生态学报, 2001, 25: 603-608

79 周广胜, 郑元润, 陈四清, 等. 自然植被净第一性生产力模型及其应用. 林业科学, 1998, 34: 2-11 
附表 1 地上生物量和生产力测定标准木参数及其回归方程 $\left.{ }^{a}\right)$

\begin{tabular}{|c|c|c|c|c|c|c|c|c|}
\hline \multirow{2}{*}{ 编号 } & \multirow{2}{*}{ 树种 } & \multirow{2}{*}{ 高度/m } & \multirow{2}{*}{$\mathrm{DBH} / \mathrm{cm}$} & \multirow{2}{*}{ 基径/cm } & \multicolumn{3}{|c|}{ 器官生物量 $/ \mathrm{kg}$} & \multirow{2}{*}{ 回归方程* } \\
\hline & & & & & 叶 & 枝 & 干 & \\
\hline 1 & \multirow{11}{*}{$\begin{array}{c}\text { 米楮 } \\
\text { (Castanopsis carlesii) }\end{array}$} & 4.3 & 2.7 & 4.4 & 0.1 & 0.8 & 1.1 & \multirow{11}{*}{$\begin{aligned} \mathrm{W}_{\mathrm{L}} & =0.0453 \mathrm{D}^{1.716} \\
\mathrm{~W}_{\mathrm{B}} & =0.037 \mathrm{D}^{2.4599} \\
\mathrm{~W}_{\mathrm{S}} & =0.1565 \mathrm{D}^{2.2772} \\
\mathrm{~W}_{\mathrm{L}} & =0.0079 \mathrm{Dr}^{2.1658} \\
\mathrm{~W}_{\mathrm{B}} & =0.0033 \mathrm{Dr}^{3.0943} \\
\mathrm{~W}_{\mathrm{S}} & =0.0179 \mathrm{Dr}^{2.8362}\end{aligned}$} \\
\hline 2 & & 2.0 & 2.8 & 4.3 & 0.2 & 0.5 & 1.4 & \\
\hline 3 & & 5.5 & 5.0 & 6.6 & 0.7 & 1.4 & 4.0 & \\
\hline 4 & & 5.0 & 4.3 & 7.3 & 0.5 & 1.4 & 2.6 & \\
\hline 5 & & 5.0 & 4.5 & - & 0.7 & 1.2 & 3.7 & \\
\hline 6 & & 16.0 & 23.5 & 21.6 & 5.9 & 21.9 & 169.1 & \\
\hline 7 & & 18.0 & 24.0 & 22.7 & 9.8 & 85.3 & 156.7 & \\
\hline 8 & & 17.0 & 26.5 & 26.1 & 11.1 & 117.6 & 196.6 & \\
\hline 9 & & 16.0 & 28.5 & 43.9 & 15.3 & 317.1 & $\begin{array}{l}190.0 \\
428.5\end{array}$ & \\
\hline 10 & & 18.0 & 28.5 & 28.5 & 10.9 & 79.4 & 207.7 & \\
\hline 11 & & 18.0 & 8.0 & 24.3 & 11.5 & 83.8 & 256.3 & \\
\hline 12 & \multirow{5}{*}{$\begin{array}{c}\text { 栲树 } \\
\text { (Castanopsis fargesii) }\end{array}$} & 2.7 & 2.8 & 3.6 & 0.2 & 0.3 & 1.0 & \multirow{5}{*}{$\begin{array}{c}\mathrm{W}_{\mathrm{L}}=4.1741 \mathrm{LnD}-3.3449 \\
\mathrm{~W}_{\mathrm{B}}=52.7863 \mathrm{LnD}-43.6809 \\
\mathrm{~W}_{\mathrm{S}}=0.1392 \mathrm{D}^{2.1917} \\
\mathrm{~W}_{\mathrm{L}}=0.0616 \mathrm{e}^{0.1166 \mathrm{Dr}} \\
\mathrm{W}_{\mathrm{B}}=0.0905 \mathrm{e}^{0.1643 \mathrm{Dr}} \\
\mathrm{W}_{\mathrm{S}}=0.4181 \mathrm{e}^{0.1479 \mathrm{Dr}}\end{array}$} \\
\hline 13 & & 3.3 & 1.8 & 12.2 & 0.1 & 0.2 & 0.5 & \\
\hline 14 & & 4.5 & 2.3 & 3.7 & 0.2 & 0.4 & 1.2 & \\
\hline 15 & & 2.5 & 2.5 & 3.0 & 0.1 & 0.1 & 1.1 & \\
\hline 16 & & 18.0 & 36.0 & 43.4 & 11.8 & 147.5 & 365.8 & \\
\hline 17 & \multirow{8}{*}{$\begin{array}{c}\text { 石栋 } \\
\text { (Lithocarpus glaber) }\end{array}$} & 4.2 & 1.3 & 1.6 & 0.1 & 0.2 & 0.3 & \multirow{8}{*}{$\begin{array}{c}\mathrm{W}_{\mathrm{L}}=0.047 \mathrm{e}^{0.2393 \mathrm{D}} \\
\mathrm{W}_{\mathrm{B}}=0.0716 \mathrm{e}^{0.3165 \mathrm{D}} \\
\mathrm{W}_{\mathrm{S}}=0.1583 \mathrm{D}^{2.2171} \\
\mathrm{~W}_{\mathrm{L}}=0.0114 \mathrm{Dr}^{2.1107} \\
\mathrm{~W}_{\mathrm{B}}=0.0114 \mathrm{Dr}^{2.7743} \\
\mathrm{~W}_{\mathrm{S}}=0.0576 \mathrm{Dr}^{2.5539}\end{array}$} \\
\hline 18 & & 2.4 & 1.2 & 2.6 & 0.1 & 0.2 & 0.3 & \\
\hline 19 & & 5.0 & 3.6 & 3.4 & 0.3 & 0.4 & 1.2 & \\
\hline 20 & & 16.0 & 18.5 & 20.6 & 1.1 & 15.7 & 101.6 & \\
\hline 21 & & 17.0 & 19.5 & 15.5 & 5.5 & 24.6 & 101.5 & \\
\hline 22 & & 17.0 & 24.0 & 25.2 & 15.5 & 126.2 & 218.6 & \\
\hline 23 & & 17.0 & 24.0 & 24.8 & 18.4 & 168.3 & 212.0 & \\
\hline 24 & & 16.0 & 17.0 & 18.2 & 5.7 & 32.8 & 92.2 & \\
\hline 25 & \multirow{6}{*}{$\begin{array}{c}\text { 细叶青冈 } \\
\text { (Cyclobalanopsis myrsinaefolia) }\end{array}$} & 2.8 & 2.2 & 3.3 & 0.1 & 0.1 & 0.8 & \multirow{6}{*}{$\begin{array}{l}\mathrm{W}_{\mathrm{L}}=0.1019 \mathrm{e}^{0.1387 \mathrm{D}} \\
\mathrm{W}_{\mathrm{B}}=0.0358 \mathrm{D}^{2.4556} \\
\mathrm{~W}_{\mathrm{S}}=0.3152 \mathrm{D}^{2.016} \\
\mathrm{~W}_{\mathrm{L}}=0.0045 \mathrm{Dr}^{2.2879} \\
\mathrm{~W}_{\mathrm{B}}=0.0024 \mathrm{Dr}^{3.262} \\
\mathrm{~W}_{\mathrm{S}}=0.0315 \mathrm{Dr}^{2.717}\end{array}$} \\
\hline 26 & & 3.5 & 1.8 & 4.7 & 0.2 & 0.2 & 0.9 & \\
\hline 27 & & 4.2 & 2.0 & 3.4 & 0.1 & 0.31 & 1.3 & \\
\hline 28 & & 11.0 & 21.5 & 17.6 & 3.6 & 37.35 & 99.6 & \\
\hline 29 & & 8.5 & 4.5 & 9.2 & 0.2 & 1.28 & 21.5 & \\
\hline 30 & & 20.0 & 45.0 & 43.7 & 40.7 & 681.96 & 699.3 & \\
\hline 31 & \multirow{6}{*}{$\begin{array}{c}\text { 木荷 } \\
\text { (Schima superb) }\end{array}$} & 4.3 & 3.5 & 4.3 & 0.3 & 0.82 & 1.9 & \multirow{6}{*}{$\begin{array}{c}\mathrm{W}_{\mathrm{L}}=0.1820 \mathrm{e}^{0.1672 \mathrm{D}} \\
\mathrm{W}_{\mathrm{B}}=0.0483 \mathrm{D}^{2.261} \\
\mathrm{~W}_{\mathrm{S}}=0.0916 \mathrm{D}^{2.3612} \\
\mathrm{~W}_{\mathrm{L}}=0.0183 \mathrm{Dr}^{1.9429} \\
\mathrm{~W}_{\mathrm{B}}=0.0282 \mathrm{Dr}^{2.4126} \\
\mathrm{~W}_{\mathrm{S}}=0.0443 \mathrm{Dr}^{2.5772}\end{array}$} \\
\hline 32 & & 14.0 & 17.5 & 15.5 & 3.9 & 37.9 & 56.4 & \\
\hline 33 & & 15.0 & 21.0 & 22.5 & 6.2 & 36.4 & 136.0 & \\
\hline 34 & & 17.0 & 25.0 & 26.1 & 10.3 & 86.8 & 189.3 & \\
\hline 35 & & 17.0 & 25.5 & 24.1 & 13.0 & 79.2 & 199.3 & \\
\hline 36 & & 18.0 & 23.0 & 26.5 & 8.9 & 46.4 & 166.8 & \\
\hline 37 & 拟赤扬(Alniphyllum axililiaris) & 11.0 & 11.5 & 12.2 & 0.4 & 3.3 & 31.7 & \multirow{5}{*}{$\begin{array}{c}\mathrm{W}_{\mathrm{L}}=0.3223 \mathrm{D}-2.5441 \\
\mathrm{~W}_{\mathrm{B}}=0.5505 \mathrm{D}-0.6728 \\
\mathrm{~W}_{\mathrm{S}}=0.2371 \mathrm{D}^{1.962} \\
\mathrm{~W}_{\mathrm{L}}=0.296 \mathrm{Dr}-2.4199 \\
\mathrm{~W}_{\mathrm{B}}=12.973 \mathrm{LnDr}-27.237 \\
\mathrm{~W}_{\mathrm{S}}=0.1128 \mathrm{Dr}^{2.1103}\end{array}$} \\
\hline 38 & 枫香(Liquidambar formosana) & 14.0 & 15.0 & - & 0.7 & 4.8 & 48.4 & \\
\hline 39 & 檫木(Sassafras tzumu) & 8.5 & 8.0 & 11.2 & 1.5 & 3.6 & 13.5 & \\
\hline 40 & 苦槠(Castanopsis sclerophylla) & 10.0 & 15.5 & 17.8 & 3.1 & 13.5 & 47.3 & \\
\hline 41 & 茅栗(Castanea seguinii) & 18.0 & 40.0 & 44.2 & 10.7 & 20.9 & 332.2 & \\
\hline
\end{tabular}

a) $*$ WL: 叶生物量; WB: 枝生物量; WS: 干生物量; Dr: 基径

附表 2 地下生物量测定标准木参数及回归方程 ${ }^{a)}$

\begin{tabular}{|c|c|c|c|c|c|}
\hline 编号 & 树种 & 高度 $/ \mathrm{m}$ & $\mathrm{DBH} / \mathrm{cm}$ & 根/kg & 回归方程* \\
\hline 1 & 红楠(Machilus thunbergii) & 5.8 & 3.6 & 0.8 & \multirow{8}{*}{$W_{R}=0.0481 D^{2.1506}$} \\
\hline 2 & 木荷(Schima superb) & 7.3 & 8.6 & 3.3 & \\
\hline 3 & 山矾(Symplocos sumuntia) & 4.6 & 4.6 & 1.1 & \\
\hline 4 & 隔药柃 (Eurya muricata) & 3.2 & 1.7 & 0.3 & \\
\hline 5 & 连芯茶(Camellia fraternna) & 6.1 & 2.9 & 0.6 & \\
\hline 6 & 米槠(Castanopsis carlesii) & 2.6 & 1.5 & 0.1 & \\
\hline 7 & 栲树(Castanopsis fargesii) & 11.5 & 19.5 & 24.0 & \\
\hline 8 & 栲树(Castanopsis fargesii) & 17.3 & 28 & 91.4 & \\
\hline
\end{tabular}

a) *WR: 根生物量 